\title{
不同施肥下农田表土有机碳含量变化分析：基于中 国农业生态系统长期试验资料
}

\author{
王成已 ${ }^{(1)}$, 潘根兴 ${ }^{(1 *}$ ，田有国 ${ }^{(2)}$, 李恋卿 ${ }^{(1)}$, 张旭辉 ${ }^{(1)}$, 韩晓君 ${ }^{(1)}$ \\ (1) 南京农业大学农业资源与生态环境研究所, 南京 210095; \\ (2) 农业部土壤肥料质量监督检验测试中心, 北京 100026 \\ * 联系人, E-mail: pangenxing@yahoo.com.cn
}

收稿日期: 2010-05-04; 接受日期: 2010-06-08

国家自然科学基金(批准号: 40710019002)、教育部基础研究重大项目和国家科技支撑计划(批准号: 2008BAD95B13-1)资助

\begin{abstract}
摘要收集整理 1979 2008 年中国长期施肥试验文献, 提取和整合了这些长期施肥试验中 农田表土有机碳的资料. 采用有效文献涉及中国大陆 23 个省区的 70 个长期试验点(其中旱地 42 个, 水田 28 个), 涵盖 16 种土壤类型. 总样本 481 个(旱地 346 个, 水田 135 个). 将施肥处 理分为 6 种类型: N: 无机氮肥; NP: 无机氮磷肥配施; NPK: 无机氮磷钾肥配施; O: 单施有机 肥; OF: 有机无机肥配施和其他非平衡施肥(如单施磷或钾, 磷钾配施和氮钾配施等). 按农田 土壤总体和区分旱地与水田两种农业利用类型, 分别统计分析一种施肥处理下表土有机碳含 量相对于特定试验对照的变化特征. 结果表明, 这些长期试验不同施肥处理下农田表土有机 碳在时间上成总体上升趋势，旱地和水田表土有机碳年均变化量分别介于-0.14 0.60 和 $-0.12 \sim 0.70 \mathrm{~g} \cdot \mathrm{kg}^{-1} \cdot \mathrm{a}^{-1}$ 之间, 年均增量分别为 0.13 和 $0.19 \mathrm{~g} / \mathrm{kg}$. 水田增长高于旱地. 不同长期试 验地点间施肥处理下, 农田表土有机碳含量积累趋势相似, 而且与单施氮肥和化肥相比, 有 机施肥和化肥配合平衡施肥普遍较大幅度提高了土壤有机碳积累速率。尽管随着试验持续时 间的延长, 土壤有机碳增幅存在下降趋势, 但良好施肥的固碳效应在旱地土壤中可持续 15 年 以上, 在稻田可持续 20 年以上，且其技术效应的幅度仍然十分明显. 因此，良好施肥管理的 推广可以作为促进中国农田生产力和土壤长期固碳潜力的重要技术途径.
\end{abstract}

关键词
长期试验
施肥
农田土壤
土壤有机碳
土壤固碳
跨地域分析

跨地域分析
土壤有机碳是农业生态系统的最重要生态因子, 对作物生产力具有重要影响 ${ }^{[1]}$. 同时, 土壤有机碳库 又是生态系统碳平衡的重要方面 ${ }^{[2]}$. 生态系统固碳被 认为是减缓大气温室气体浓度而控制全球升温的主 要途径之一. IPCC AR4(2007)提出, 农业温室气体减 排潜力 $90 \%$ 来自土壤固碳 ${ }^{[3]}$. 近年来, 国内外科学界 对农业土壤有机碳动态及其固碳意义进行了较多研
究, 从全国尺度 ${ }^{[4]}$ 和省级尺度 $^{[5]}$, 以及长期试验区域 对比 ${ }^{[6]}$ 阐明了中国农田土壤有机碳的增长, 提出了农 田土壤固碳特别是水稻土固碳可以作为中国农业提 高粮食生产力和缓减气候变化的重要途径 ${ }^{[7,8]}$. 土壤 固碳潜力及其计量成为当前面向全球气候变化的地 学和生态学研究的前沿. 但是, 合理和可靠地估计土 壤固碳潜力, 需要综合考虑气候、土壤类型、农业管

英文版见: Wang C J, Pan G X, Tian Y G, et al. Changes in cropland topsoil organic carbon with different fertilizations under long-term agro-ecosystem experiments across mainland China. Sci China Life Sci, 2010, 53: 858 - 867, doi: 10.1007/s11427-010-4028-y 
理措施的影响, 考虑自然生物潜力和技术影响下的 潜力 ${ }^{[9]}$.

改善作物管理及其生产力的农业活动包括耕作、 施肥和灌溉等, 对土壤有机碳含量及储存有着快速 和强烈的影响. 20 世纪 70 年代末以来, 中国陆续建 立了一些肥料和耕作活动的农业生态系统长期试验, 对于这些不同的农业活动对土壤有机碳和生产力变 化影响的个案研究已有过很多报道 ${ }^{[10 ~ 14]}$. 但是, 关 于这些农业活动对中国农田土壤有机碳动态总体影 响的研究还很少, 不足以用来评估影响农田有机碳 的最大施肥因子和最大影响幅度, 因而还未能充分 地评估这些管理措施下的土壤固碳潜力. 采用若干 南方稻田长期试验的跨地域分析得以阐明稻田有机 质积累与水稻产量的关系和稻田土壤固碳的多过程 和机制的相互作用 ${ }^{[15,16]}$. 采用农业部耕地监测、资料 的跨地域分析得以阐明不同地区土壤管理与作物生 产对土壤有机质增加的总体影响 ${ }^{[17]}$. 最近, 对分布于 全国的保护性耕作的长期试验资料进行了跨地域分 析, 揭示了结合秥秆还田的保护性耕作而非单纯的 少免耕显著提高了土壤有机碳储量并促进了作物生 产力 ${ }^{[18]}$.

为评价不同施肥对中国农田土壤有机碳动态的 总体影响, 探讨促进农田固碳和提高作物生产力的 最佳施肥途径, 收集了分布于全国不同地区的 70 个 代表性施肥农业生态系统长期试验的资料, 采用归 一化处理和相对年变化量的分析方法, 研究长期不 同施肥下中国农田土壤有机碳含量的总体变化, 并 比较早地和水田土壤差异, 判析试验持续年限长短 对土壤有机碳动态的影响, 为农田固碳减排和粮食 生产可持续发展提供施肥管理依据.

\section{1 材料与方法}

\section{1 数据来源}

检索中国期刊网和维普科技期刊网, 收集 1979 年 1 月 2008 年 6 月间有关中国长期定位施肥试验的 研究论文, 提取其中试验站点、土壤类型、作物系统、 监测时间、施肥处理、有机碳(质)及产量数据, 整理 为长期施肥试验下农田表土有机碳及产量的数据库. 采集数据符合如下原则: (1) 施肥处理为施无机肥, 有机肥及有机无机肥配施等, 且在报道的试验监测 期内管理方式一致; (2) 试验年限 $\geq 6$ 年, 且试验的起
止年份清楚; (3) 试验小区面积 $\geq 10 \mathrm{~m}^{2}$; (4) 表土有机 碳含量测定方法相同, 各处理下土壤有机碳(质)的初 始值和变化值明确; (5) 试验以不施肥为对照. 满足 上述要求的文献有 76 篇, 涉及分布于 23 个省 (区、市) 的 70 个长期试验点(其中旱地 42 个, 水田 28 个)(附 表 1). 涵盖 16 种土壤类型. 不同处理的样本总数 481 个(其中旱地 346 个, 水田 135 个).

\section{2 数据处理}

首先将施肥处理分为 6 种类型: $\mathrm{N}$ : 无机氮肥; NP: 无机氮磷肥配施; NPK: 无机氮磷钾肥配施; O: 单施有机肥; OF: 有机无机肥配施和其他非平衡施肥 (如单施磷或钾, 磷钾配施和氮钾配施等). 将记载的 肥料施用量按照中国肥料网有关标准分别折合成 $\mathrm{N}$, $\mathrm{P}_{2} \mathrm{O}_{5}$ 和 $\mathrm{K}_{2} \mathrm{O}$ 的年养分施用量. 本研究中, 旱地年肥料 施用量介于 $24 \sim 1810 \mathrm{~kg} / \mathrm{hm}^{2}$, 而水田介于 $17 \sim 3317$ $\mathrm{kg} / \mathrm{hm}^{2}$. 有机碳数据的处理和计算如下:

(1) 有机碳原始数据归一化处理. 将原始数据 集中土壤有机质 $(\mathrm{SOM})$ 数据全部转化为土壤有机碳 (SOC) 数据 $(\mathrm{g} / \mathrm{kg})$, 因为有机质平均含 $58 \%$ 的碳, 前者 乘以有机碳转换系数 0.58 .

(2) 试验期间不同处理下有机碳含量年变化量 计算. 分别计算试验期间内对照和处理的有机碳平 均年变化量 $\left(\mathrm{g} \cdot \mathrm{kg}^{-1} \cdot \mathrm{a}^{-1}\right)^{[4]}$, 按下式:

$$
\mathrm{AI}=\left(\mathrm{SOC}_{t}-\mathrm{SOC}_{0}\right) / t
$$

式中, $\mathrm{AI}$ 为平均年变化量 $\left(\mathrm{g} \cdot \mathrm{kg}^{-1} \cdot \mathrm{a}^{-1}\right) ; t$ 为试验观测 期限(年), 由试验观测的终止年与起始年的差值得到; $\mathrm{SOC}_{0}$ 和 $\mathrm{SOC}_{t}$ 分别为试验观测起始年和终止年的有 机碳含量测定值.

(3) 施肥处理下有机碳含量年变化量计算. 为 了区分施肥处理的实际影响, 需要扣除非处理下表 土有机碳的变化效应. 这里提出有机碳相对年变化 量(relative annual change, RAC, $\mathrm{g} \cdot \mathrm{kg}^{-1} \cdot \mathrm{a}^{-1}$ ) 概念, 即 试验观测期限内任一施肥处理(TR)扣除对照(CK) 后 的平均净年变化量 ${ }^{[4]}$ :

$$
\mathrm{RAC}=\left(\left(\mathrm{SOC}_{t}-\mathrm{SOC}_{0}\right)_{\mathrm{TR}}-\left(\mathrm{SOC}_{t}-\mathrm{SOC}_{0}\right)_{\mathrm{CK}}\right) / t .
$$

于是, 有:

$$
\mathrm{RAC}=\mathrm{AI}_{\mathrm{TR}}-\mathrm{AI}_{\mathrm{CK}}
$$

\section{3 数据处理与显著性检验}

考虑到不同种植制度下农田土壤固碳的差异性, 按旱地与水田两种农业利用类型进行统计比较分析. 
所有数据都以基于试验处理重复的平均值正负标准 差表示. 数据处理在 Microsoft Excel 2003 进行, 农田 类型、施肥处理间 RAC 差异采用 TTEST 和 SPSS(Version 13.0)进行差异显著性检验 $(P<0.05$ 和 $P<0.01)$.

\section{2 结果与讨论}

\section{1 长期试验基点土壤有机碳变化总体分布}

计算的所有不同试验基点的长期不同施肥处理 下有机碳年增长幅度的频度分布见图 1. 在统计的 481 个试验处理样本中, 有 $94 \%$ 的样本有机碳随试验 持续而增加, 仅 $6 \%$ 的样本减小. 计算得到的这些施 肥试验基点的农田有机碳相对增量介于 $-0.14 \sim 0.70$ $\mathrm{g} \cdot \mathrm{kg}^{-1} \cdot \mathrm{a}^{-1}$ (平均为 $0.15 \mathrm{~g} \cdot \mathrm{kg}^{-1} \cdot \mathrm{a}^{-1}$ ), 其中旱地介于 $-0.14 \sim 0.60 \mathrm{~g} \cdot \mathrm{kg}^{-1} \cdot \mathrm{a}^{-1}$ (平均为 $0.13 \mathrm{~g} \cdot \mathrm{kg}^{-1} \cdot \mathrm{a}^{-1}$ ), 水田 介于 $-0.12 \sim 0.70 \mathrm{~g} \cdot \mathrm{kg}^{-1} \cdot \mathrm{a}^{-1}$ (平均为 $0.19 \mathrm{~g} \cdot \mathrm{kg}^{-1} \cdot \mathrm{a}^{-1}$ ) (表 1). 无论是旱地还是水田, 都是约 $50 \%$ 样本的 RAC 值集中在 $0 \sim 0.2 \mathrm{~g} \cdot \mathrm{kg}^{-1} \cdot \mathrm{a}^{-1}$. Pan 等人 ${ }^{[4]}$ 对大田土 壤监测资料的分析表明, 中国农田土壤表土有机碳
年增长量为 $(0.076 \pm 0.219) \mathrm{g} / \mathrm{kg}$, 其中稻田为 $(0.110 \pm$ $0.244) \mathrm{g} / \mathrm{kg}$, 旱地为 $(0.056 \pm 0.200) \mathrm{g} / \mathrm{kg}$. 这些长期施 肥试验中有机碳的年增长量明显高于大田土壤的变 化幅度. 可见, 施肥作为农业主要管理活动可以明显 提高土壤的有机碳水平, 尽管不同地点和不同施肥 处理下的增量存在较大差异.

\section{2 不同施肥处理下土壤有机碳含量变化}

表 2 显示不同施肥处理下土壤有机碳含量的变 化. 旱地土壤不同施肥处理下有机碳相对年增长量 的变化是: $\mathrm{O}, \mathrm{OF}>\mathrm{NPK}, \mathrm{N}, \mathrm{NP}$. 而水田则是: $\mathrm{O}$, $\mathrm{OF}>\mathrm{NPK}>\mathrm{N}, \mathrm{NP}$. 有机肥的处理 $(\mathrm{O}$ 和 $\mathrm{OF}$ 处理 $)$ 下, 旱 地土壤有机碳年增量平均达到 0.23 和 $0.22 \mathrm{~g} / \mathrm{kg}$, 而 水田下达到 0.28 和 $0.30 \mathrm{~g} / \mathrm{kg}$. 而不同无机肥处理下, 旱地土壤有机碳年增量介于 $0.02 \sim 0.10 \mathrm{~g} / \mathrm{kg}$, 水田介 于 $0.03 \sim 0.11 \mathrm{~g} / \mathrm{kg}$. 其中, NPK复合施肥处理下年增量 最高, 旱地和水田平均达到 0.10 和 $0.11 \mathrm{~g} / \mathrm{kg}$, 非平衡 施肥 $(\mathrm{N}, \mathrm{NP}$ 和其他非平衡施肥处理下)旱地和水田分 别是 $0.02 \sim 0.07$ 和 $0.03 \sim 0.04 \mathrm{~g} / \mathrm{kg}$. 表明, 有机施肥和 有机无机配合施肥 $(\mathrm{O}$ 和 $\mathrm{OF}$ 处理) 有机碳含量的提高

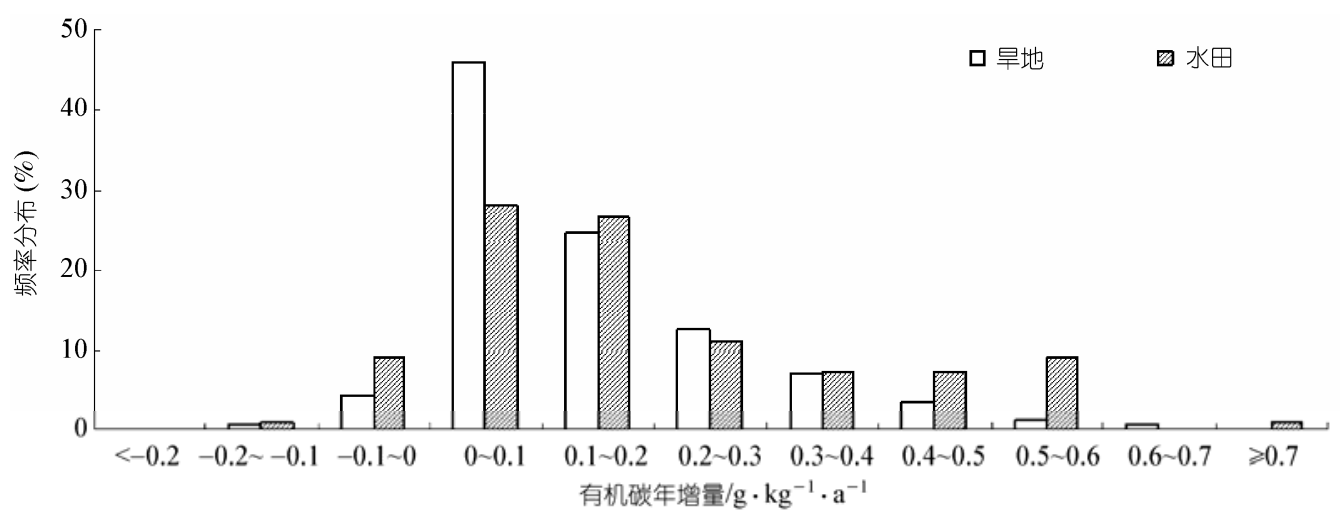

图 1 供试试验基点表土有机碳相对年增量频度分布

表 1 不同农田类型土壤有机碳动态分布 ${ }^{\text {a) }}$

\begin{tabular}{|c|c|c|c|c|c|c|}
\hline 农田类型 & 有机碳动态 & 样本数 & 相对增量 & 总体增量 & 试验持续年限 & 平均年限 \\
\hline \multirow{2}{*}{ 旱地 $(n=346)$} & 增加 & $329(95.09 *)$ & $0.14 \pm 0.13$ & \multirow{2}{*}{$0.13 \pm 0.13 b$} & $14.46 \pm 5.31$ & \multirow{2}{*}{$14.42 \pm 5.27$} \\
\hline & 减少 & $17(4.91)$ & $-0.04 \pm 0.04$ & & $13.53 \pm 4.60$ & \\
\hline \multirow{2}{*}{ 水田 $(n=135)$} & 增加 & 122(90.37) & $0.21 \pm 0.18$ & \multirow{2}{*}{$0.19 \pm 0.18 \mathrm{a}$} & $14.63 \pm 4.22$ & \multirow{2}{*}{$14.39 \pm 4.24$} \\
\hline & 减少 & $13(9.63)$ & $-0.03 \pm 0.03$ & & $12.15 \pm 3.93$ & \\
\hline \multirow{2}{*}{ 合计 $(n=481)$} & 增加 & $451(93.76)$ & $0.16 \pm 0.14$ & \multirow{2}{*}{$0.15 \pm 0.15$} & $14.51 \pm 5.03$ & \multirow{2}{*}{$14.41 \pm 5.00$} \\
\hline & 减少 & $30(6.24)$ & $-0.04 \pm 0.04$ & & $12.93 \pm 4.31$ & \\
\hline
\end{tabular}

a) 同一列的小写字母分别示 $P<0.05$, 差异显著; *: 括号内为所占百分比 
幅度是化肥配施的约 2 倍, 而后者又是不平衡化肥施 用的约 2 倍. 前者可以认为是直接增加了秸秆、厩肥 等有机物质输入的结果. 但是, 没有直接施入有机物 质的化肥平衡施肥(NPK 处理)下有机碳的年增长量 较高与施肥下作物产量的提高而直接增加了有机物 质输入有关 ${ }^{[10,19]}$. 反之, 不平衡施肥下 (N, NP 处理) 土壤有机碳年增长量最小, 除了旱地 NP 处理下平均 达到 $0.07 \sim 0.11 \mathrm{~g} / \mathrm{kg}$ 外, 其他处理为 $0.02 \sim 0.04 \mathrm{~g} / \mathrm{kg}$. 这同样可以归结于产量的降低减少了有机物质输入. 当然, 氮素单一养分的增加可能刺激土壤呼吸而减 少有机碳储存.

\section{3 长期施肥下有机碳动态随试验持续时间的变化}

供试长期试验的时间跨度介于 6 25 年, 按照几 个不同的持续年限的组合, 分别计算其有机碳相对 年增量, 结果见表 3. 可知, 旱地土壤中不同处理下 土壤有机碳平均年增量有随着试验持续时间的延长 而降低的趋势, 而水田中则没有表现出这种趋势. 在 持续 20 年以上时, 旱地土壤的平均年增量显著低于 20 年以下的试验观测的年增幅, 而水田土壤的增量 下降幅度仍不显著. 但是, 在旱地土壤中年增幅较高 的观测值分布于 $6 \sim 15$ 年的持续期限内, 而水田则 分布于 11 20 年持续时间内. 许信旺 ${ }^{[20]}$ 根据土壤监 测的有机碳变化与监测时间期限的关系提出, 旱地 土壤的固碳持续期可达 34 年, 而水田土壤则可达 27 年. 这里的试验期限都短于这些估计的持续期限, 在监测期 20 年以上仍还达年增量 0.07 0.16 g/ $/ \mathrm{kg}$ 的
水平, 远高于 Pan 等人 ${ }^{[19]}$ 由常规大田土壤监测资料得 出的有机碳积累速率. 可见，施肥下的固碳持续期 可能比常规农业管理下的更长. 不过, 利用短期的试 验数据来估算有机碳累计量时, 可能会出现高估的 问题.

图 2 是按不同施肥处理分别统计的土壤有机碳 相对年增量与试验持续期限的关系. 在试验期限 20 年内, 有机施肥、复合施肥与不平衡施肥的有机碳年 增量的差异幅度十分明显, 但试验持续到 20 年以上 时，它们的差异明显变小，说明旱地土壤中良好施肥 对土壤有机碳储量的增加作用仅能在 20 年持续. 相 反, 水田土壤中, 这种差异在持续 20 年以上仍十分 显著，有机施肥下仍可达到化肥配合施肥下的 2 倍, 而后者又是单施氮肥等不平衡施肥下的 2 倍. 因此, 稻田良好施肥下土壤固碳效应不但可以持续 20 年以 上，而且在较长时期内有机施肥和化肥配施等良好 施肥技术仍可达到显著的固碳效应.太湖地区稻田 持续 22 年的长期试验支持了有机无机配合施肥相对 于化肥单施的增产作用与固碳作用 ${ }^{[19]}$. 该结果也支 持了本实验室提出的稻田土壤固碳增产双赢作用, 且稻田土壤的增碳潜力显著大于旱地土壤的认 识 ${ }^{[4,7,8]}$. 因此, 经营和管理稻田土壤不仅对于粮食生 产，而且对农业增产增汇减排都具有重要意义.

\section{3 结论}

通过对长期施肥试验文献数据的整合分析，得

表 2 不同施肥处理下土壤有机碳相对年增量 $(\mathrm{g} / \mathrm{kg})$ 及年养分施用量 $\left.(\mathbf{k g} / \mathbf{h m})^{2}\right)^{\mathrm{a})}$

\begin{tabular}{|c|c|c|c|c|c|c|c|c|}
\hline & \multirow{2}{*}{ 农田类型 } & \multicolumn{7}{|c|}{ 施肥处理 } \\
\hline & & $\mathrm{N}$ & $\mathrm{NP}$ & NPK & $\mathrm{O}$ & OF & 其他 & 合计 \\
\hline \multirow{3}{*}{$\begin{array}{c}\text { 旱地 } \\
(n=346)\end{array}$} & 样本数 & 33 & 76 & 44 & 49 & 106 & 38 & 346 \\
\hline & 相对年增量 & $0.04 \pm 0.08 b c$ & $0.07 \pm 0.05 b$ & $0.10 \pm 0.09 b$ & $0.23 \pm 0.14 \mathrm{a}$ & $0.22 \pm 0.13 \mathrm{a}$ & $0.02 \pm 0.04 \mathrm{c}$ & $0.13 \pm 0.13 B$ \\
\hline & 平均养分施用量 & $177.65 \pm 74.87$ & $\begin{array}{c}240.34 \pm 111.9 \\
9\end{array}$ & $517.26 \pm 375.06$ & $329.09 \pm 310.93$ & $620.22 \pm 299.46$ & $188.94 \pm 140.39$ & - \\
\hline \multirow{3}{*}{$\begin{array}{c}\text { 水田 } \\
(n=135)\end{array}$} & 样本数 & 7 & 12 & 31 & 17 & 53 & 15 & 135 \\
\hline & 相对年增量 & $0.03 \pm 0.04 \mathrm{c}$ & $0.04 \pm 0.04 \mathrm{c}$ & $0.11 \pm 0.11 b$ & $0.28 \pm 0.20 \mathrm{a}$ & $0.30 \pm 0.17 \mathrm{a}$ & $0.03 \pm 0.08 \mathrm{c}$ & $0.19 \pm 0.18 \mathrm{~A}$ \\
\hline & 平均养分施用量 & $191.77 \pm 96.85$ & $\begin{array}{c}329.66 \pm 168.1 \\
5\end{array}$ & $497.10 \pm 198.77$ & $826.94 \pm 828.05$ & $741.49 \pm 515.13$ & $248.06 \pm 188.58$ & - \\
\hline \multirow{3}{*}{$\begin{array}{c}\text { 合计 } \\
(n=481)\end{array}$} & 样本数 & 40 & 88 & 75 & 66 & 159 & 53 & 481 \\
\hline & 相对年增量 & $0.04 \pm 0.07 b$ & $0.06 \pm 0.05 b$ & $0.11 \pm 0.10 b$ & $0.24 \pm 0.16 a$ & $0.24 \pm 0.15 a$ & $0.03 \pm 0.05 b$ & $0.15 \pm 0.15$ \\
\hline & 平均养分施用量 & $180.12 \pm 77.92$ & $\begin{array}{c}252.52 \pm 123.8 \\
5\end{array}$ & $508.93 \pm 312.82$ & $457.32 \pm 536.94$ & $660.65 \pm 387.58$ & $205.67 \pm 155.96$ & - \\
\hline
\end{tabular}


a) 同一行小写字母示不同施肥处理间 RAC 差异 $(P<0.05)$; 同一列大写字母示不同农田类型间 RAC 差异 $(P<0.05)$. N: 无机氮肥; NP: 无机氮磷肥配施; NPK: 无机氮磷钾肥配施; O: 纯有机肥; OF: 无机有机肥配施; 其他: 其他非平衡施肥

到如下结论：(1) 长期不同施肥试验条件下，农田表 肥特别是施有机肥及有机肥与无机肥配施能显著提 土有机碳含量总体呈增加趋势, 而水田中比旱地中高土壤有机碳增加幅度; (3) 良好施肥的有机碳快速 年增长幅度更大，水田更有利于促进有机碳积累; (2) 增加效应在旱地土壤中持续不到 20 年, 而水田中仍 无论是旱地还是水田, 与不平衡施肥相比较, 平衡施 然可以持续到 20 年以上. 本研究表明, 施肥管理在

表 3 土壤有机碳相对年增量 $\left(\mathrm{g} \cdot \mathrm{kg}^{-1} \cdot \mathrm{a}^{-1}\right)$ 随试验持续期限的变化 ${ }^{\mathrm{a})}$

\begin{tabular}{ccccccc}
\hline \multirow{2}{*}{} & \multirow{2}{*}{ 农田类型 } & \multicolumn{5}{c}{ 试验持续期限/年 } \\
\cline { 3 - 7 } & & $6 \sim 10$ & $11 \sim 15$ & $16 ~ 20$ & $21 \sim 25$ & 合计/平均 \\
\hline 早地 & 样本数 & 101 & 89 & 110 & 46 & 346 \\
$(n=346)$ & 相对年增量 & $0.19 \pm 0.15 \mathrm{a}$ & $0.15 \pm 0.14 \mathrm{a}$ & $0.10 \pm 0.09 \mathrm{ab}$ & $0.07 \pm 0.07 \mathrm{~b}$ & $0.13 \pm 0.13 \mathrm{~B}$ \\
\hline 水田 & 样本数 & 36 & 36 & 47 & 16 & 135 \\
$(n=135)$ & 相对年增量 & $0.15 \pm 0.18 \mathrm{a}$ & $0.20 \pm 0.18 \mathrm{a}$ & $0.21 \pm 0.19 \mathrm{a}$ & $0.16 \pm 0.14 \mathrm{a}$ & $0.19 \pm 0.18 \mathrm{~A}$ \\
\hline 合计 & 样本数 & 137 & 125 & 157 & 62 & 481 \\
$(n=481)$ & 相对年增量 & $0.18 \pm 0.16 \mathrm{a}$ & $0.16 \pm 0.16 \mathrm{a}$ & $0.13 \pm 0.14 \mathrm{ab}$ & $0.09 \pm 0.10 \mathrm{~b}$ & $0.15 \pm 0.15$ \\
\hline
\end{tabular}

a) 同一行小写字母示不同监测时间内 $\mathrm{RAC}$ 差异 $(P<0.05)$; 同一列大写字母示不同农田类型间 $\mathrm{RAC}$ 差异 $(P<0.05)$
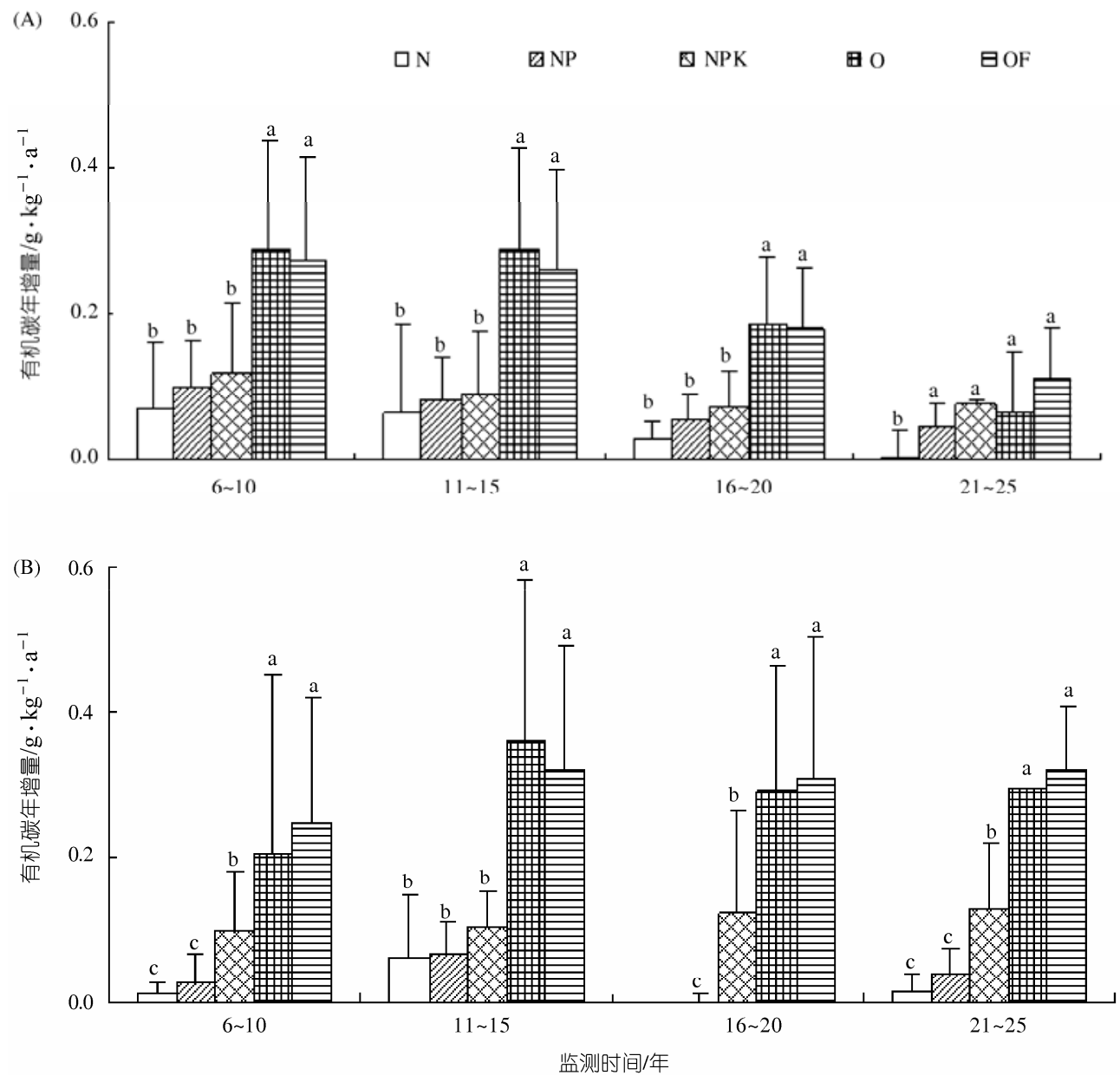


\section{图 2 不同施肥处理下有机碳相对年增量随试验持续时间的变化}

(A) 旱地; (B) 水田

中国农田固碳增汇中具有重要作用, 特别是稻田良 好施肥的固碳潜力十分明显, 可以作为提高农田生 产力和固碳潜力的重要途径.

尽管这些试验因设计的研究目的及观察内容存
在差异, 但跨地域的数据分析得以反映长期不同施 肥下中国农田表土有机碳含量变化特点. 今后仍需 对不同施肥条件下固碳减排增汇的机理及管理技术 的综合效应作进一步研究.

\section{参考文献}

1 Pan G X, Smith P, Pan W N. The role of soil organic matter in maintaining the productivity and yield stability of cereals in China. Agric Ecosyst Environ, 2009, 129: 344-348

2 Piao S L, Fang J Y, Ciais P, et al. The carbon balance of terrestrial ecosystems in China. Nature, 2009, 458, doi: 10.1038/nature07944

3 Smith P, Martino D, Cai Z C, et al. Policy and technological constraints to implementation of greenhouse gas mitigation options in agriculture. Agric Ecosyst Environ, 2007, 118: 6-21

4 Pan G X, Xu X W, Smith P, et al. An increase in topsoil SOC stock of China's croplands between 1985 and 2006 revealed by soil monitoring. Agric Ecosyst Environ, doi: 10.1016/j.agee.2009.12.011

5 Liao Q L, Zhang X H, Li Z P, et al. Increase in soil organic carbon stock over the last two decades in China's Jiangsu Province. Glob Change Biol, 2009, 15: 861-875

6 周萍, 潘根兴, 李恋卿, 等. 南方典型水稻土长期试验下有机碳积累机制研究 V. 碳输入与土壤碳固定. 中国农业科学, 2009, 42: $4260-4268$

7 潘根兴, 赵其国. 我国农田土壤碳库演变研究全球变化和国家粮食安全. 地球科学进展, 2005, 20: 384一 393

8 潘根兴. 中国土壤有机碳库及其演变与应对气候变化. 气候变化研究进展, 2008, 4: 277-284

9 孙文娟, 黄耀, 张稳, 等. 农田土壤固碳潜力研究的关键科学问题. 地球科学进展, 2008, 23: 996-1004

10 潘根兴, 周萍, 张旭辉, 等. 不同施肥对水稻土作物碳同化与土壤碳固定的影响一以太湖地区黄泥土肥料长期试验为例. 生态学报, 2006, 26: 3704-3710

11 古巧珍, 杨学云, 孙本华, 等. 长期定位施肥对土娄土耕层土壤养分和土地生产力的影响. 西北农业学报, 2004, 13: 121一125

12 张少民, 郝明德, 陈否. 黄土高原长期施肥对小麦产量及土壤肥力的影响. 干旱地区农业研究, 2006, 24: 85一 89

13 张洁, 姚宇卿, 吕军杰, 等. 半湿润偏旱区坡耕地保护耕作土壤碳素转化及增产机理. 中国生态农业学报, 2008, 16: 297一301

14 孟否, 蔡祖聪, 丁维新. 长期施肥对土壤碳储量和作物固定碳的影响. 土壤学报, 2005, 42: 769-776

15 周萍, Alessandro P, 潘根兴, 等. 三种南方典型水稻土长期试验下有机碳积累机制研究III. 两种水稻土颗粒有机质结构特征的变化. 土壤学报, 2009, 46: 398-405

16 周萍, 宋国菡, 潘根兴, 等. 三种南方典型水稻土长期试验下有机碳积累机制研究 II. 团聚体内有机碳的化学结合机制. 土壤学报, 2009, 46: $263-273$

17 程琨, 潘根兴, 田有国, 等. 中国农田表土有机碳含量变化特征一一基于国家耕地土壤监测数据. 农业环境科学学报, 2009, 28: 2476一 2481

18 王成己, 潘根兴, 田有国. 保护性耕作下农田表土有机碳含量变化特征分析一基于中国农业生态系统长期试验资料. 农业环境科 学学报, 2009, 28: 2464-2475

19 Pan G X, Zhou P, Li Z P, et al. Combined inorganic/organic fertilization enhances N efficiency and increases rice productivity through organic carbon accumulation in a rice paddy from the Tai Lake region, China. Agric Ecosyst Environ, 2009, 131: 274-280

20 许信旺. 不同地理尺度下中国农田土壤有机碳分布与变化. 南京农业大学博士研究生毕业论文, 2008: 54一81 
附表 1 供试长期施肥试验站点情况 ${ }^{\text {a) }}$

\begin{tabular}{|c|c|c|c|c|c|c|c|}
\hline 试验站点 & 土壤类型 & 作物系统 & 管理措施 & 小区面积 $/ \mathrm{m}^{2}$ & 持续时段/年 & 建站时间/年 & 文献 \\
\hline 安徽怀远 & 青黏土 & 小麦-玉米 & $\mathrm{CF}$ & 33 & 1992 2000 & 1992 & 詹其厚等, 2006 \\
\hline 安徽黄山 & 水稻土 & 早稻-晚稻 & CF; O; OF; S & 20 & 1987 1995 & 1987 & 刘枫等, 1998 \\
\hline 安徽蒙城 & 砂姜黑土 & 小麦-大豆 & $\mathrm{CF}$ & 19 & 1995 2004 & 1994 & 王道中等, 2007 \\
\hline 安徽濉溪 & 砂姜黑土 & 小麦-大豆 & $\mathrm{CF} ; \mathrm{O} ; \mathrm{OF}$ & 180 & 1981 1996 & 1981 & 曹承富等, 2003 \\
\hline 北京昌平 & 潮土 & 冬小麦-夏玉米 & $\mathrm{CF} ; \mathrm{O} ; \mathrm{OF}$ & 480 & 1984 2003 & 1984 & 黄斌等, 2006 \\
\hline 北京昌平 & 潮土 & 冬小麦-夏玉米 & $\mathrm{CF} ; \mathrm{OF} ; \mathrm{S}$ & 200 & 1990 2004 & 1990 & 李秀英等, 2006 \\
\hline 甘肃定西 & 黑垆土 & 小麦 & $\mathrm{CF} ; \mathrm{O} ; \mathrm{OF}$ & 40 & 1990 1999 & 1990 & 兰晓泉等, 2001 \\
\hline 甘肃张掖 & 灌漠土 & 春小麦 & $\mathrm{CF} ; \mathrm{O} ; \mathrm{OF}$ & 32 & 1993 2003 & 1993 & 陈修斌等, 2005 \\
\hline 广东广州 & 水稻土 & 早稻-晚稻 & $\mathrm{CF} ; \mathrm{O} ; \mathrm{OF}$ & 16 & 1983 1992 & 1983 & 周修冲等, 1994 \\
\hline 广东增城 & 水稻土 & 早稻-晚稻 & $\mathrm{CF} ; \mathrm{OF}$ & 66.7 & 1987 2003 & 1987 & 张磷等, 2005 \\
\hline 河北昌黎 & 褐土 & 小麦-玉米 & $\mathrm{CF} ; \mathrm{OF} ; \mathrm{S}$ & 48 & 1990 1998 & 1990 & 韩志卿等, 2000 \\
\hline 河北衡水 & 潮土 & 小麦-玉米 & $\mathrm{CF} ; \mathrm{O}$ & 30 & 1979 2002 & 1979 & 李科江等, 2007 \\
\hline 河北衡水 & 潮土 & 冬小麦-夏玉米 & CF; O; OF; S & 67 & 1981 2004 & 1981 & 马俊永等, 2007 \\
\hline 河北辛集 & 潮土 & 冬小麦-夏玉米 & $\mathrm{CF} ; \mathrm{O} ; \mathrm{OF}$ & 80 & 1980 1996 & 1980 & 史吉平等, 2002 \\
\hline 河北遵化 & 褐土 & 小麦-大豆 & CF; OF; S & 48 & 1995 2002 & 1995 & 韩志卿等, 2003 \\
\hline 河南封丘 & 潮土 & 小麦-大豆 & $\mathrm{CF} ; \mathrm{O} ; \mathrm{OF}$ & 66.7 & 1989 2005 & 1984 & 王俊华等, 2007 \\
\hline 河南开封 & 潮土 & 小麦-大豆 & $\mathrm{CF} ; \mathrm{O} ; \mathrm{OF}$ & 10 & 1988 1994 & 1987 & 刘春增等, 1996 \\
\hline 河南汝南 & 砂姜黑土 & 冬小麦-夏大豆 & $\mathrm{CF}$ & 20 & 1981 1997 & 1981 & 孙克刚等, 1999 \\
\hline 河南郑州 & 潮土 & 小麦-大豆 & $\mathrm{CF} ; \mathrm{O} ; \mathrm{OF}$ & 46.7 & 1980 1995 & 1980 & 孙克刚等, 1996 \\
\hline 河南驻马店 & 潮土 & 花生 & $\mathrm{CF}$ & 20 & 1997 2003 & 1997 & 甄志高等, 2006 \\
\hline 黑龙江海伦 & 黑土 & 玉米 & $\mathrm{CF}$ & 63 & 1990 2004 & 1978 & 林德喜等, 2006 \\
\hline 黑龙江海伦 & 黑土 & 玉米 & $\mathrm{CF} ; \mathrm{O} ; \mathrm{OF}$ & 224 & 1985 2004 & 1978 & 赵丽娟等, 2006 \\
\hline 黑龙江黑河 & 暗棕壤 & 小麦 & CF; O; OF; S & 220 & 1979 1994 & 1979 & 张振江, 1998 \\
\hline 黑龙江密山 & 白浆土 & 春小麦 & $\mathrm{CF} ; \mathrm{O} ; \mathrm{NT}$ & 79 & 1987 2005 & 1987 & 曾玲玲等, 2007 \\
\hline 湖北通城 & 水稻土 & 早稻-晚稻 & $\mathrm{CF} ; \mathrm{OF}$ & 20 & 1981 2001 & 1981 & 王传雷等, 2003 \\
\hline 湖北武汉 & 水稻土 & 水稻-小麦 & $\mathrm{CF} ; \mathrm{O} ; \mathrm{OF}$ & 40 & 1981 2002 & 1981 & 乔艳等, 2007 \\
\hline 湖南衡阳 & 红壤 & 玉米-小麦 & $\mathrm{CF} ; \mathrm{O} ; \mathrm{OF}$ & 200 & 1990 2003 & 1990 & 王伯仁等, 2005 \\
\hline 湖南宁乡 & 水稻土 & 玉米-水稻 & $\mathrm{CF} ; \mathrm{O} ; \mathrm{OF} ; \mathrm{S}$ & 66.7 & $1986 \sim 2003$ & 1986 & 李新爱等, 2006 \\
\hline 湖南祁阳 & 红壤 & 小麦-玉米 & CF; O; OF; S & 196 & 1990 2000 & 1990 & 徐明岗等, 2006 \\
\hline 湖南桃江 & 水稻土 & 玉米-水稻 & CF; O; OF; S & 66.7 & $1986 \sim 2003$ & 1986 & 李新爱等, 2006 \\
\hline 湖南桃源 & 水稻土 & 水稻-水稻-绿肥 & $\mathrm{CF} ; \mathrm{O} ; \mathrm{OF}$ & 32 & 1990 2004 & 1978 & 王开峰等, 2007 \\
\hline 湖南武冈 & 水稻土 & 水稻-水稻-绿肥 & CF; O; OF; S & 66.7 & 1986 2003 & 1986 & 李新爱等, 2006 \\
\hline 湖南新化 & 水稻土 & 水稻-水稻-绿肥 & $\mathrm{CF} ; \mathrm{O} ; \mathrm{OF} ; \mathrm{S}$ & 66.7 & 1986 2003 & 1986 & 李新爱等, 2006 \\
\hline 湖南株洲 & 水稻土 & 水稻-水稻-绿肥 & $\mathrm{CF} ; \mathrm{O} ; \mathrm{OF} ; \mathrm{S}$ & 66.7 & $1986 \sim 2003$ & 1986 & 李新爱等, 2006 \\
\hline 吉林德惠 & 黑土 & 玉米 & CF; O; OF; S & 50 & 1999 2005 & 1999 & 王光华等, 2007 \\
\hline 吉林公主岭 & 黑土 & 玉米 & $\mathrm{CF} ; \mathrm{O} ; \mathrm{OF}$ & 100 & 1980 1993 & 1980 & 孙宏德等, 1995 \\
\hline 吉林梅河口 & 水稻土 & 水稻 & $\mathrm{CF} ; \mathrm{O} ; \mathrm{OF}$ & 20 & 1983 1988 & 1983 & 柳金来等, 1990 \\
\hline 江苏常熟 & 水稻土 & 水稻-小麦 & CF; OF; S & 20 & 1990 2001 & 1987 & 李腊梅等, 2006 \\
\hline 江苏吴江 & 水稻土 & 水稻-油菜 & CF; OF; S & 25 & 1987 2004 & 1987 & 潘根兴等, 2006 \\
\hline 江苏徐州 & 潮土 & 小麦-玉米 & $\mathrm{CF} ; \mathrm{O} ; \mathrm{OF}$ & 33 & 1980 1999 & 1980 & 张爱君等, 2001 \\
\hline
\end{tabular}


续附表 1

\begin{tabular}{|c|c|c|c|c|c|c|c|}
\hline 试验站点 & 土壤类型 & 作物系统 & 管理措施 & 小区面积/m² & 持续时段/年 & 建站时间/年 & 文献 \\
\hline 江苏镇江 & $\begin{array}{l}\text { 黄棕壤 } \\
\end{array}$ & 早稻-晚稻 & CF; OF; S & 48 & $1983 \sim 1997$ & 1983 & 徐阳春等, 2000 \\
\hline 江西进贤 & 水稻土 & 早稻-晚稻 & $\mathrm{CF} ; \mathrm{OF}$ & 46.7 & 1981 2003 & 1981 & 郭菊花等, 2007 \\
\hline 江西进贤 & 红壤 & 早玉米-晚玉米 & $\mathrm{CF} ; \mathrm{O} ; \mathrm{OF}$ & 22.2 & 1986 1996 & 1986 & 史吉平等, 2002 \\
\hline 江西鹰潭 & 水稻土 & 早稻-晚稻 & $\mathrm{CF}$ & 33.3 & 1991 2004 & 1985 & 李成亮等, 2007 \\
\hline 辽宁凤城 & 棕壤 & 玉米 & $\mathrm{CF} ; \mathrm{O} ; \mathrm{OF}$ & 60 & 1992 2006 & 1992 & 董旭等, 2008 \\
\hline 辽宁喀左 & 褐土 & 棉花 & CF; O; OF; S & 72 & $1987 \sim 1998$ & 1987 & 张璐等, 2002 \\
\hline 辽宁盘锦 & 水稻土 & 玉米 & CF; O; OF; S & 100 & 1978 1985 & 1978 & 李焕珍等, 1986 \\
\hline 辽宁沈阳 & 棕壤 & 玉米 & $\mathrm{CF} ; \mathrm{O} ; \mathrm{OF}$ & 31.5 & 1979 2002 & 1979 & 刘小虎等, 2005 \\
\hline 辽宁沈阳 & 棕壤 & 玉米 & $\mathrm{CF} ; \mathrm{O} ; \mathrm{OF}$ & 69 & 1987 1994 & 1987 & 穆琳等, 1998 \\
\hline 辽宁瓦房店 & 棕壤 & 玉米-大豆 & $\mathrm{O} ; \mathrm{S}$ & 100 & 1986 1995 & 1986 & 赵秀兰等, 1998 \\
\hline 辽宁瓦房店 & 草甸土 & 玉米-大豆 & $\mathrm{O} ; \mathrm{S}$ & 100 & 1988 1994 & 1988 & 赵秀兰等, 1998 \\
\hline 山东禹城 & 潮土 & 冬小麦-夏玉米 & $\mathrm{CF} ; \mathrm{O} ; \mathrm{OF}$ & 28 & $1986 \sim 2000$ & 1979 & 唐继伟等, 2006 \\
\hline 山西河曲 & 褐土 & 糜子-土豆 & $\mathrm{CF} ; \mathrm{O} ; \mathrm{OF}$ & 24 & 1988 2005 & 1988 & 王改兰等, 2006 \\
\hline 陕西长武 & 黑垆土 & 小麦 & $\mathrm{CF} ; \mathrm{O} ; \mathrm{OF}$ & 66 & 1984 2004 & 1984 & 陈否等, 2007 \\
\hline 陕西合阳 & 褐土 & 小麦 & $\mathrm{CF} ; \mathrm{OF} ; \mathrm{S}$ & 20 & 1990 2000 & 1990 & 方日尧等, 2003 \\
\hline 陕西杨凌 & 褐土 & 小麦-玉米 & CF; OF; S & 19.8 & 1977 2002 & 1977 & 高瑞等, 2006 \\
\hline 陕西杨凌 & 褐土 & 冬小麦-夏玉米 & $\mathrm{CF} ; \mathrm{OF} ; \mathrm{S}$ & 196 & 1990 2002 & 1990 & 古巧珍等, 2004 \\
\hline 陕西杨凌 & 黑钙土 & 小麦 & $\mathrm{CF} ; \mathrm{O} ; \mathrm{OF}$ & 66 & $1984 \sim 1990$ & 1984 & 王彩线等, 2000 \\
\hline 上海郊区 & 水稻土 & 小麦-水稻-水稻 & CF; O; OF; S & 133 & 1979 1993 & 1979 & 汪寅虎等, 1994 \\
\hline 四川遂宁 & 水稻土 & 水稻 & $\mathrm{CF} ; \mathrm{O} ; \mathrm{OF}$ & 120 & 1985 1995 & 1985 & 袁玲等, 1997 \\
\hline 四川武胜 & 水稻土 & 水稻 & $\mathrm{CF} ; \mathrm{O} ; \mathrm{OF}$ & 120 & 1983 1999 & 1983 & 郑兰君等, 2001 \\
\hline 天津西青 & 潮土 & 冬小麦-夏玉米 & $\mathrm{CF} ; \mathrm{OF}$ & 16.7 & 1979 2003 & 1979 & 任顺荣等, 2006 \\
\hline 新疆阜康 & 灰漠土 & 小麦 & $\mathrm{CF} ; \mathrm{OF} ; \mathrm{S}$ & 66 & 1991 2004 & 1987 & 周斌等, 2007 \\
\hline 新疆乌市 & 灰漠土 & 玉米-春小麦 & $\mathrm{CF} ; \mathrm{OF}$ & 468 & 1990 2002 & 1990 & 许咏梅等, 2005 \\
\hline 云南楚雄 & 水稻土 & 水稻-小麦 & $\mathrm{CF} ; \mathrm{O} ; \mathrm{OF}$ & 20 & 1987 1998 & 1987 & 王绍明, 2000 \\
\hline 浙江杭州 & 水稻土 & 小麦-水稻-水稻 & $\mathrm{CF} ; \mathrm{O} ; \mathrm{OF}$ & 111 & 1991 2002 & 1991 & 王胜佳等, 2004 \\
\hline 浙江杭州 & 水稻土 & 小麦-水稻-水稻 & $\mathrm{CF} ; \mathrm{O} ; \mathrm{OF}$ & 30 & 1997 2006 & 1997 & 徐祖祥, 2007 \\
\hline 浙江睢州 & 水稻土 & 小麦-水稻-水稻 & $\mathrm{CF} ; \mathrm{OF}$ & 33.3 & 1992 1997 & 1992 & 吴槐泓等, 2000 \\
\hline 浙江矔州 & 水稻土 & 小麦-水稻-水稻 & $\mathrm{CF} ; \mathrm{OF}$ & 200 & 1988 1997 & 1988 & 吴槐泓等, 2000 \\
\hline 浙江䀪州 & 水稻土 & 小麦-水稻-水稻 & $\mathrm{CF} ; \mathrm{OF}$ & 33.3 & $1983 \sim 1997$ & 1983 & 吴槐泓等, 2000 \\
\hline 重庆北碚 & 水稻土 & 水稻 & $\mathrm{CF} ; \mathrm{OF}$ & 120 & 1985 1995 & 1985 & 袁玲等, 1997 \\
\hline
\end{tabular}

a) CF: 化肥(包括元素肥的单施和配施); O: 单施有机肥; OF: 有机无机肥配施; S: 秥秆还田 